\title{
GRANDES PROJETOS ECONÔMICOS (GPE) NA VOLTA GRANDE DO XINGU: IMPLICAÇÕES SOCIOESPACIAIS NO MUNICÍPIO DE VITÓRIA DO XINGU
}

\author{
Italla Cristina Neves ${ }^{1}$ \\ Edilane Bezerra Amorim ${ }^{2}$ \\ Márcio Douglas Amaral ${ }^{3}$
}

\begin{abstract}
RESUMO
O presente estudo parte da premissa de pensar estrategicamente o desenvolvimento regional a partir do planejamento e gestão do território. Deste modo, a pesquisa tem como objetivo central analisar as mudanças nas práticas de gestão e ordenamento territorial em Vitória do Xingu a partir da implantação da Usina Hidrelétrica de Belo Monte (UHBM), pois ordenamento territorial é entendido como sendo um instrumento de articulação interinstitucional e de articulação transetorial, que tem como objetivo um planejamento integrado e articulado junto à ação pública, consequentemente, dado à compatibilidade de políticas públicas no rebatimento do espaço integrado à ação do poder público. Portanto, compete estabelecer um diagnóstico do território, aferindo as demandas de modo que venha compor o escopo do artigo, articulado com as políticas públicas nas quais permitirá analisar o rebatimento do ordenamento e gestão territorial que visa realizar os objetivos estratégicos impostos pelo governo. Desta forma, tem como propósito projetar meios de transformação para sociedade, estabelecendo relações possíveis para o desvelamento do real, buscando elementos e conexões entre os diferentes aspectos que caracterizam a realidade, deste modo o fenômeno investigado é analisado ou compreendido a partir da totalidade.
\end{abstract}

Palavras-chave: Amazônia. Território. Ordenamento Territorial.

\begin{abstract}
This study starts from the premise of strategically thinking regional development from the planning and management of the territory. Thus, the main objective of the research is to analyze the changes in management and land management practices in Vitória do Xingu from the implementation of the Belo Monte Hydroelectric Power Plant (UHBM), as land use planning is understood as an instrument of articulation. interinstitutional and cross-sectoral articulation, which aims at integrated planning and

\footnotetext{
${ }^{1}$ Graduada em Geografia pela Universidade Federal do Pará/Campus Universitário de Altamira, 2013. Mestrado em Geografia pelo Programa de Pós Graduação em Geografia - PPGEO pela Universidade Federal do Pará UFPA/Campus Belém, 2017; Doutoranda em Geografia pelo Programa de Pós Graduação em Geografia PPGEO pela Universidade Federal do Pará - UFPA/Campus Belém, 2019 e membro/pesquisador do Laboratório de Geografia Desenvolvimento e Dinâmicas Territoriais na Amazônia (GEDTAM). Pesquisas temas como, Desenvolvimento Regional e Território, Grandes Projetos na Amazônia Brasileira. E-mail: italla.neves1605@gmail.com

${ }^{2}$ Graduada em Licenciatura Plena em Geografia pela Universidade Federal do Pará/Campus de Altamira (turma 2015) Mestranda do Programa de Pós-Graduação em Geografia - Universidade Federal do Pará (IFCH/UFPA). Pesquisadora do Laboratório de Estudos das Dinâmicas Territoriais na Amazônia (LEDTAM). Pesquisa temas nas área de Geografia Agrária. Coordenadora do projeto Práticas Indissociáveis de Ensino Pesquisa e Extensão - PIEPE. Pesquisadora da Rede Pesquisa Xingu - Redex. E-mail: edilany.f5@hotmail.com

${ }^{3}$ Possui graduação em Licenciatura Plena em Pedagogia pela Universidade do Estado do Pará (2001), graduação em Bacharelado e Licenciatura Plena em Geografia pela Universidade Federal do Pará (2003), mestrado em Planejamento do Desenvolvimento - Nucleo de Altos Estudos Amazonicos (2005) e doutorado em Geografia (Geografia Humana) pela Universidade de São Paulo (2011). Em 2014 desenvolveu estágio de Pós-Doutorado na Universidade Federal do Sul e Sudeste do Pará. Atualmente é professor adjunto da Universidade Federal do Pará e diretor da Faculdade de Geografia e Cartografia da UFPA. Tem experiência na área de Geografia, com ênfase em Geografia Urbana, atuando principalmente nos seguintes temas: Metropolização, cidades médias, planejamento e gestão urbanos, Amazônia. E-mail: marcioamaral29@gmail.com
} 
articulated with public action, consequently, given the compatibility of public policies, in the rebound of space, integrated into the action of public power. Therefore, it is incumbent to establish a diagnosis of the territory, gauging the demands, so that it will compose the scope of the article, articulated with the public policies, in which it will allow to analyze the rebounding of the territorial planning and management that aims to accomplish the strategic objectives imposed by the government. Thus, its purpose is to project means of transformation for society, establishing possible relationships for the unveiling of the real, seeking elements and connections between the different aspects that characterize reality, thus the investigated phenomenon is analyzed or understood from the totality.

Keywords: Amazon. Territory. Land use planning.

\section{RESUMEN}

Este estudio parte de la premisa de pensar estratégicamente el desarrollo regional a partir de la planificación y gestión del territorio. Por lo tanto, el objetivo principal de la investigación es analizar los cambios en las prácticas de gestión y gestión de la tierra en Vitória do Xingu desde la implementación de la Central Hidroeléctrica Belo Monte (UHBM), ya que la planificación del uso de la tierra se entiende como un instrumento de articulación. articulación interinstitucional e intersectorial, que tiene como objetivo la planificación integrada y articulada con la acción pública, en consecuencia, dada la compatibilidad de las políticas públicas, en el rebote del espacio, integrado en la acción del poder público. Por lo tanto, corresponde establecer un diagnóstico del territorio, midiendo las demandas, de modo que componga el alcance del artículo, articulado con las políticas públicas, que permitirá analizar el rebote de la planificación y gestión territorial que apunta a lograr los objetivos estratégicos impuestos por el gobierno. Así, su propósito es proyectar medios de transformación para la sociedad, estableciendo posibles relaciones para la revelación de lo real, buscando elementos y conexiones entre los diferentes aspectos que caracterizan la realidad, de esta forma el fenómeno investigado se analiza o comprende desde la totalidad.

Palabras clave: Amazon. Territorio. Planificación territorial.

\section{INTRODUÇÃO}

A região Amazônica enfrenta constantemente processos de crescimento econômico para seu desenvolvimento por meio de propostas elaboradas, sobretudo, por representantes do Poder Político para ser incorporada à lógica capitalista (KOHLHEPP, 2002). Nas últimas décadas a ocupação da Amazônia se dá por meio da administração do Estado em políticas e projetos de desenvolvimento por meio da construção e instalação de infraestrutura com forte presença de capital privado e estrangeiro, pois a região é considerada importantíssima por ter recursos naturais abundantes.

Visto a importância da Amazônia em contexto global, é importante frisar que seu crescimento está vinculado ao movimento do capital em função de suprir as necessidades do país em se estabelecer como agroexportador em contexto internacional, cujo o propósito é expandir as relações econômicas sob as recentes fronteiras estabelecidas por esta lógica.

A crescente discussão acerca do desenvolvimento da Amazônia é apontada pelas notáveis mudanças que ocorrem na região devido à implementação dos Grandes Projetos 
Econômicos ou apenas relatados como Grandes Projetos que constituem a importante compreensão deste cenário atualmente vivenciado na região.

O caminho para a compreensão do processo de desenvolvimento contemporâneo de determinada região está acompanhado das grandes empresas e ao Estado, a forma do modus operandi revela os meios e instrumentos entre o poder econômico e político envolvidos no processo de acumulação, estes processos resultam em dois produtos importantes que são o aumento da desigualdade e a concentração de riqueza, consequentemente as disparidades existentes entre eles.

Partindo do ponto de vista territorial, notam-se as manifestações decorrentes dos processos políticos, econômicos e sociais que moldam não apenas a região, modifica o espaço vivido, pois desvela as contradições latentes no tecido social e nas relações estabelecidas entre a sociedade e a natureza. Cabe interpretar a complexidade de tais processos espaciais que compõem a diferenciação do território face à implementação da UHE Belo Monte no município de Vitória do Xingu no estado do Pará, pois ao pensar o Estado como agente harmonizador no ordenamento territorial, é visto, ao contrário, como gerador de impactos negativos em questões ambientais, sociais e econômicos.

Portanto, questiona-se que as relações exógenas, que permeiam no território da região de integração do Xingu reordena relações políticas e econômicas em favor dos grandes projetos como Belo Monte, os quais modificam os espaços e as relações estabelecidas no território, sobrepondo aos interesses do poder público local e das populações tradicionais.

Outro questionamento levantado é que em virtude da verticalização de interesses, temse aumentado a exploração dos recursos naturais, agregando pouco valor ao trabalho e ao produto explorado, dando continuidade ao processo histórico amazônico, meramente exportador de matéria-prima, sem levar em consideração o desenvolvimento das populações locais.

Do ponto de vista territorial são evidentes as manifestações dos processos econômicos, sociais e políticos que moldam a região enquanto espaço vivido (LEFEBVRE, 1991), pois desvela as contradições latentes no tecido social, e nas relações estabelecidas entre a sociedade e a natureza. Sendo tais diferenciações observadas no território a partir da construção da UHE Belo Monte, ao discorrer acerca da pesquisa será realizado um estudo aprofundado para melhor compreender a dinâmica dos processos territoriais das áreas (in)diretamente afetadas pela inserção deste empreendimento. Vale ressaltar que estas reflexões fazem parte de uma pesquisa maior que propõe discutir o modelo de desenvolvimento e suas implicações no ordenamento e gestão do território do Xingu. 


\section{GESTÃO, PLANEJAMENTO E ORDENAMENTO TERRITORIAL: UMA BREVE DISCUSSÃO TEÓRICO-METODOLÓGICA}

Para a presente pesquisa é fundamental adentrar nos conceitos de gestão e ordenamento territorial antes de apontar algumas implicações empíricas das suas possíveis transformações em Vitória do Xingu. Neste sentido, a gestão deve sempre ser articulada ao planejamento, pois conforme aponta Souza (2013), enquanto a gestão se refere ao curto prazo, ao "aqui e agora", às situações imediatas e rotineiras, o planejamento, ao contrário, faz referência aos médio e longo prazos, portanto, ao futuro, buscando "prever" a evolução dos processos, problemas e dificuldades geradas. De todo modo, o autor propõe que as duas sejam trabalhadas em conjunto.

Além do planejamento e da gestão, outro termo fundante da pesquisa é o ordenamento territorial, entendido como propõe Herrera e Moreira (2017), “ordenamento territorial tem haver, antes, com (concepções ideológicas, formação histórico-cultural e valores locais) na análise das ações políticas, no encaminhamento de projetos como formas de reestruturação do local", ou seja, como uma tentativa de ordenar as atividades humanas, por meio de direcionamentos dados por planos políticos e institucionais.

A utilização do termo gestão territorial vem sendo foco de discussões, assim como casos diversos, este vem sendo reproduzido como "dissonância cognitiva", ou seja, onde conceitos parecem idênticos, porém o significado não coincide. Na atualidade, este termo é utilizado por diversos setores para designar processos ou atividades de ações públicas de regulação, investimentos, de instituições entre outros, de agregação de valor para a localidade, conquistas ou até mesmo expansão de mercados (DUNCAN, 2009).

O sentido tradicional da palavra "gestão" faz referência a uma suposta existência de organização, seja ela material ou imaterial, pois agrega recursos, pessoas e/ou entidades, interagindo em um determinado espaço. A gestão territorial é entendida como uma determinada ação que decorre de uma ação dos sistemas de governança na execução de políticas públicas, assim como a transparência e controle das ações de interesse geral.

A gestão territorial também se refere ao exercício da soberania do Estado-Nação em determinado território. Segundo o referencial político, é previsto na legislação, a qual regula constantemente as relações estabelecidas do Estado-sociedade, que ao ser ditadas pelo poder hegemônico e pelas ações coletivas buscam alternativas condizentes para alterar as relações de poder existentes no território. 
$\mathrm{Na}$ sua concepção mais atual, a "gestão territorial" tem o sentido de ordenar os papéis dos atores na gestão dos processos de desenvolvimento, promovendo a articulação de instrumentos públicos e privados, mediando conflitos de interesses, promovendo a divulgação sobre os projetos em andamento, influindo, assim, na distribuição e uso do poder no âmbito de um dado território, objeto de intervenção de uma ação pública (DUNCAN, 2009, p. 22).

Deste modo, a gestão territorial está intimamente ligada aos processos de tomada de decisões dos atores sociais, institucionais e econômicas sobre a apropriação e o uso dos territórios (DALLABRIDA, 2007). Portanto, o interesse maior surge no campo de políticas públicas, pois são encontradas políticas de ordenamento para o uso dos recursos territoriais: tais como as políticas voltadas para a saúde, infraestrutura e para a educação, para que haja um desenvolvimento equilibrado no território.

Ao abordarmos a questão de ordenamento territorial, faz-se necessário atribuir aos principais conceitos envolvidos, pois dará significado à categoria de análise que melhor se enquadra na discussão da pesquisa, portanto, que de forma introdutória o território deve ser entendido na abordagem de Santos (2006):

O território não é apenas o conjunto dos sistemas naturais e de sistemas de coisas
superpostas. O território tem que ser entendido como o território usado, não o
território em si. O território usado é o chão mais a identidade. A identidade é o
sentimento de pertencer àquilo que nos pertence. O território é o fundamento do
trabalho, o lugar da residência, das trocas materiais e espirituais e do exercício da
vida. O território em si não é uma categoria de análise em disciplinas históricas,
como a Geografia. É o território usado que é uma categoria de análise. Aliás, a
própria ideia de nação, e depois a ideia de Estado Nacional, decorrem dessa relação
tornada profunda (SANTOS, 2006, p. 14).

Trabalhar com o conceito de "ordenamento territorial", torna-se uma tarefa delicada como antes mencionada e não é algo fácil, pois para entender este conceito, precisamos, antes de tudo, construir uma concepção acerca de ordem e território, sendo estes amplamente discutidos nos últimos anos, seja por conta do discurso de fluidez ou mesmo, no limite, o desaparecimento dos territórios. Contudo, como aponta Haesbaert (2006) precisamos compreender esta problemática, precisamos nos reportar "às transformações recentes na desordem mundial", e pensar a partir das reflexões teóricas que têm seu marco na então chamada "condição pós-moderna".

Como aponta Haesbaert (2006), a "Ordem" é indissociável da "Desordem", que não pode ser simplesmente entendida a priori, "pois ela pode estar sendo a manifestação de uma nova ordem, de um novo ordenamento". O território, "enquanto relação de apropriação e/ou domínio da sociedade sobre o seu espaço, não está relacionado apenas à fixidez e à estabilidade", o território incorpora "como um de seus constituintes fundamentais o 
movimento", que traz distintas formas de mobilidade, ou seja, como o autor denomina, o território não é apenas um "território-zona", mas também um "território-rede", dado suas relações serem múltiplas e complexas.

Na concepção de Gómez-Orea (1993), o ordenamento territorial é entendido em termos conceituais como a "projeção no espaço das políticas social, cultural, ambiental e econômica de uma sociedade". O ordenamento territorial está relacionado umbilicalmente à perspectiva de desenvolvimento adotada, pois esse estilo de desenvolvimento determina o modelo territorial, que por sua vez, é uma expressão da sociedade e dos seus conflitos.

Ainda segundo Gómez-Orea (1993), faz-se ordenamento territorial no momento em que se considera o território na definição das estratégias de desenvolvimento, bem como quando são articuladas a ele atividades que acabam por configurar a referida estratégia. Como destaca o autor:

[...] a ordenação do território é uma função pública que responde a necessidade de
controlar o crescimento espontâneo das atividades humanas, fundamentalmente, no
sentido de evitar problemas e desequilíbrios que aquele provoca entre zonas e entre
setores, optando por um tipo de justiça sócio-espacial e por um conceito de
qualidade de vida que transcende ao mero crescimento econômico (GÓMEZ-
OREA,1993, p.2).

Nessa mesma direção, Lopes (apud CONDESSO, 2001), entende o Ordenamento "como um ato de gestão do planeamento das ocupações, um potenciar da faculdade de aproveitamento das infraestruturas existentes e o assegurar da prevenção de recursos limitados". Portanto, de forma simplificada, é a forma de gestão da interatividade com a natureza, ou seja, o espaço físico.

O crescente debate acerca do "desenvolvimento" é comumente confundido com grandes projetos de investimentos econômicos, porém não devem ser confundidos com projeto de desenvolvimento, seja ele local, regional ou nacional. Bueno Sánchez (1990, p.7) aponta que "o desenvolvimento econômico e social de uma determinada região ou país deve estar ligado intrinsicamente a elevar a qualidade de vida da população, desde o indivíduo à totalidade que o integra".

Deste modo, destacamos os esforços de determinadas políticas de desenvolvimento e a luta para inclusão de ações para que haja melhorias à qualidade de vida e para que haja a realização plena do ser humano enquanto ser social. De acordo com o modelo de desenvolvimento adotado no Brasil, este é realizado através da exportação de commodities e a especialização produtiva, em detrimento do crescimento econômico que foi construído historicamente pelo modelo de industrialização articulado pelos ciclos econômicos. 
Os resquícios advindos do passado, esse movimento do grande capital está intrinsicamente ligado ao Estado, cujo seu apoio é fundamental, mesmo tendo um discurso liberal. Deste modo, essa associação de interesses foi particularmente interessante para adoção de políticas neoliberais, neste período o Estado renuncia suas funções de propulsor de políticas de desenvolvimento, cujo foco era favorável à grande maioria, com isso escondendo por traz de coordenações pelo poder privado, que é o oposto, pois nesse caso a sociedade não tem representatividade no que almeja.

A perspectiva aqui adotada dialoga com a teoria aberta do desenvolvimento socioespacial proposta por Souza (2013). Neste sentido, a discussão do desenvolvimento passa pelo entendimento da autonomia individual e coletiva, pela justiça social e pela qualidade de vida. Não se trata, portanto, de simplesmente relacionar desenvolvimento à modernização territorial, menos ainda à desenvolvimento econômico numa visão eurocêntrica e teleológica.

Definitivamente o desenvolvimento socioespacial refere-se a um processo de enfrentamento da heteronomia e tendo a autonomia como um horizonte de pensamento e ação, é uma antítese ético-política do "desenvolvimento econômico" capitalista. São ideias antípodas: se situam em posições diametralmente opostas uma a outra, nos planos filosóficos e teóricos (SOUZA, 2013, p. 274).

Na proposta de Souza (2013) o desenvolvimento socioespacial adota parâmetros subordinados e subordinadores. Estes se referem, acima de tudo, à autonomia que é entendida a partir da obra de Castoriadis como a capacidade da sociedade se autodeterminar ou se autoinstituir tanto em termos individuais, a efetiva liberdade individual, quanto em termos coletivos, à possibilidade de autogoverno e de autodeterminação coletiva.

Àqueles, os parâmetros subordinados, referem-se a justiça social, que tem relação com a simetria, a equidade e a igualdade efetiva de oportunidades a todos os sujeitos; e a qualidade de vida, entendida não somente como melhorias materiais, como no padrão de vida, mas também como melhorias imateriais.

Dessa forma, quando formos olhar para realidade empírica de Vitória do Xingu, na terceira parte deste artigo, procuraremos destacar os elementos do desenvolvimento socioespacial nos termos aqui apresentados e não simplesmente o desenvolvimento entendido como crescimento econômico ou modernização territorial como tem-se feito tradicionalmente.

Mediante a este cenário apontado, percebe-se que os investimentos regionais são pensados e constituídos essencialmente pelos Projetos de Aceleração do Crescimento - PAC, visto que alguns são realizados apenas pelo incentivo do Estado ou empresas estatais, outros estão inseridos no contexto indireto com forte presença de financiamentos públicos como 
também há presença do BNDES e outros aliados ao capital privado internacional. Face a estes investimentos do grande capital, os demais atores não são devidamente representados, sendo espoliados em detrimento das grandes decisões.

Portanto, o ordenamento territorial é entendido como sendo um instrumento de articulação interinstitucional e de articulação transetorial, que tem como objetivo um planejamento integrado e articulado junto à ação pública e, consequentemente, dado a compatibilidade de políticas públicas no rebatimento do espaço integrado à ação do poder público.

Mediante o exposto, faz-se necessário elaborar políticas de ordenamento territorial baseando-se na capacidade e potencialidade do poder local, que ao articular-se aos diferentes grupos sociais, tais projetos possam atuar como incentivadores para o desenvolvimento territorial da região que esteja espacialmente equilibrado.

Partindo das hipóteses levantadas, a execução do ordenamento e gestão territorial na região de integração deve buscar compreender a dinâmica local e este emaranhado de instrumentos de intervenção territorial que historicamente foi imposta à Amazônia brasileira e que possa funcionar de maneira integrada e em harmonia com os interesses, consequentemente, a geração de efeitos positivos para a população amazônica.

Finalizando essa discussão teórica, considera-se importante acrescentar à perspectiva de desenvolvimento socioespacial de Souza (2013) a dimensão da endogenia e da sustentabilidade para se pensar o desenvolvimento territorial da Amazônia.

Como sustenta Boisier (1997) o desenvolvimento deve ser cada vez mais considerado em termos endógenos, uma vez que tem uma relação direta e estreita com a cultura local e com os valores nela incluídos. Muito embora existam valores universais, tais como o valor à vida, à liberdade, por exemplo, a grande maioria tem um caráter particular, voltado aos interesses da sociedade local. Essa visão de Boisier (1997) acaba por contrariar a ideia de que no contexto atual da globalização e da mobilidade espacial do capital, o desenvolvimento e o crescimento territorial são realizados de forma exógena. De forma sintética o autor indica que:

La endogeneidad del desarrollo regional habría que entenderla como um fenómeno que se presenta en por lo menos cuatro planos que se contan, se cruzan entre sí.

Primero, la endogeneidad se refiere o se manifiesta en el plano político, en ele cual se le identifica como uma creciente capacidade regional para tomar las decisiones relevantes en relación a diferentes opciones de desarrollo, diferentes estilos de desarrollo, y em relación al uso de los instrumentos correspodientes, o sea, la capacidade de diseñar y ejecutar políticas de desarrollo, y sobre todo, la capacidade de negociar. Em segundo lugar, la endogeneidad se manifiesta en el plano económico, y se refiere em este caso a la apropiación y reinversion regional, dándole al mismo tempo uma base permanente de sutentación em el largo plazo...En tercer lugar, la endogeneidad es también interpretada en el plano científico y tecnológico, 
es dicir, la vemos como la capacidad interna de um sistema - en este de um território organizado - para generar sus propios implulsos tecnológicos de cambio, capaces de provocar modificaciones cualitativas en el sistema. Em cuarto lugar, la endogeneidad se plantea en el plano de la cultura, como una suerte de matriz generadora de la identidade socioterritorial (BOISIER, 1993, p. 14).

A dimensão ambiental, da sustentabilidade, segundo Dallabrida (2000), se apresenta como um desafio ao ordenamento territorial sustentável, pois o atual contexto socioeconômico, político e cultural, é marcado por uma série de denúncias de situações de insustentabilidade, dentre as quais se pode destacar: a eliminação de florestas; a exaustão e a contaminação química dos solos; a contaminação e o rebaixamento dos níveis das águas potáveis; a contaminação dos oceanos; o alto consumo da camada de ozônio; a elevação das temperaturas globais e do nível dos mares; diferenciados níveis de poluição ambiental, etc. (DALLABRIDA, 2000). Este autor faz questão de destacar que a sustentabilidade não deve ser entendida como aquela defendida pelas grandes instituições internacionais, cujos eixos centrais do discurso são a eficiência, a escala, a equidade, a autossuficiência e a ética, contudo, orientados pela lógica do mercado e sem colocar como horizonte a redução das desigualdades sociais e regionais, bem como o uso racional dos recursos naturais.

A visão aqui defendida é ainda mais radical, no sentido de que busca aquilo que Acselrad; Mello; Bezerra (2009) tem chamado de justiça ambiental que sustenta a necessidade de demonstrar as desigualdades social, racial, sexual, gênero por traz dos problemas ambientais. Nestes termos a justiça ambiental é maior que as disciplinas acadêmicas, incorporando as lutas e os movimentos contra as injustiças existentes no bojo do Estado de direito e da própria sociedade.

No caso das regiões de fronteira, Acselrad; Mello; Bezerra (2009) fazem questão de apontar que o imperativo da produção de divisas e a busca pelo crescimento econômico continuam por colonizar as dinâmicas territoriais do país e produzindo injustiças ambientais. A produção de matérias-primas e commodities continuam a sacrificar pequenos agricultores familiares, populações indígenas e extrativistas. Portanto, na visão desses autores, enquanto o capitalismo puder transferir para os mais pobres os males ambientais, a pressão sobre o ambiente não terá fim. $\mathrm{O}$ que impõe como possibilidade apenas a luta e a mobilização em torno dos direitos universais.

\section{A IMPLANTAÇÃO DA USINA HIDRELÉTRICA DE BELO MONTE NA REGIÃO DO XINGU}

A Amazônia atual é o "produto das interações entre a sociedade e a natureza que foi se construindo ao longo do tempo, as questões sociais e ecológicas se configuram no recorte 
territorial e não existem em função do nível de desenvolvimento, mas sim do modelo exógeno adotado" (FERREIRA; SALATI, 2005). Face à exploração dos recursos naturais, em específico no estado do Pará, está fortemente ligada aos abusos e usos, em sua maior parte, de forma ilegal, dos recursos naturais que, consequentemente, causa tensões sociais em determinadas regiões e o crescimento de violentos conflitos pelo uso e posse da terra.

Portanto, a partir da criação de condições gerais de caráter político, seria possível estabelecer atividades dos diferentes grupos e órgãos sociais através de suas reivindicações e direito do uso da terra e dos recursos naturais de forma sustentável, pautados num desenvolvimento regional adequado às necessidades socioeconômicas da sociedade direta e indiretamente envolvida.

Nas últimas décadas tem-se observado a crescente preocupação em acelerar o crescimento dos municípios do Pará, em detrimento do plano estratégico de resgate do planejamento e gestão do território, portanto, o Programa de Aceleração do Crescimento PAC, que mesmo reduzido em função da atual crise econômica brasileira, tem seu importante papel em direcionar os projetos e aplicação dos recursos, assim garantindo o financiamento estatal na instalação de grandes projetos ligados ao setor energético.

O PAC contribuiu de maneira decisiva e elevou o investimento público e privado em obras fundamentais para o desenvolvimento da região. A construção do Empreendimento Hidrelétrico de Belo Monte, no seu contexto histórico, demonstra complexidade até sua consolidação, considerando todas as fases, arranjos necessários e reformulações no projeto para que se minimizasse os impactos socioeconômicos e ambientais.

Dadas todas as modificações no projeto, a UHE Belo Monte foi construída no município de Vitória do Xingu, como mostra o mapa de localização abaixo descrito. A construção conta com duas casas de força, a casa de força principal conta 18 unidades geradoras e tem capacidade de geração de 11.000,0 MW. A segunda unidade geradora, denominada casa de força complementar conta com 6 unidades geradoras que em seu total gera em torno de 233,1 MW. No que tange à área de influência direta apontada no EIARIMA, destaca-se uma atenção especial aos aspectos éticos, culturais e socioeconômicos. 
Figura 01. Mapa de localização de Vitória do Xingu

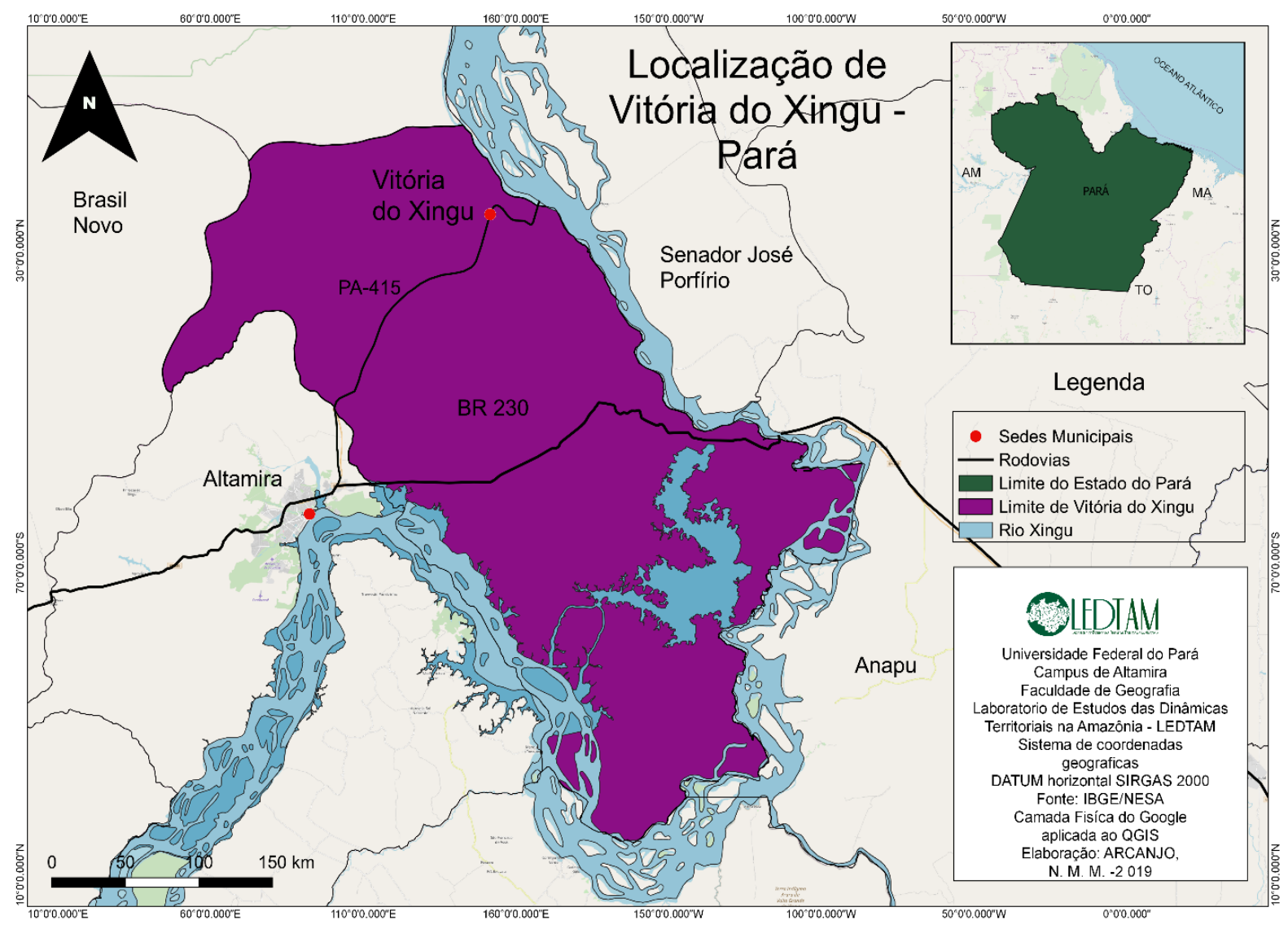

Fonte: IBGE/NESSA

Elaboração: ARCANJO

Deste modo, a UHE Belo Monte é um objeto, como é explicitado por Milton Santos (1988), “que não só está inserido neste processo de grandes mudanças como também incorpora uma série delas, bem como lhe são impostas também estas alterações, o que modifica não só sua forma, como sua própria natureza".

O projeto UHEBM desde sua idealização, no período da ditadura militar, até chegar à fase política democrática no Brasil, é pensado e desenhado com o propósito de levar o desenvolvimento ao país, e com isso perpassou mais de 30 anos até a construção de Belo Monte e, consequentemente, houve uma longa trajetória de conflitos envoltos não apenas deste empreendimento, mas um conjunto maior e mais amplos de projetos que serão implantados na Amazônia em si, em especial no estado do Pará.

Portanto, o presente estudo parte da premissa de pensar estrategicamente o desenvolvimento regional a partir da questão do planejamento e gestão do território, pois trata-se da construção e transformação do território regional face à implantação de grandes projetos e seus rebatimentos na organização territorial de Vitória do Xingu-PA, apesar de não haver um espaço legalmente reconhecido de tratamento das dinâmicas regionais, há um forte 
desenvolvimento nessa região com a construção do Empreendimento Hidrelétrico de Belo Monte que já está em processo de finalização da obra.

Compreende-se que selecionar o território em que haja capacidade de conexão do local ao global, sobretudo, a partir da exploração dos recursos naturais, permite a capacidade de atrair o capital tanto nacional quanto internacional e cabe à discussão, pois condiciona e leva à precarização do Espaço e das relações socialmente construídas na área diretamente afetada. Como podemos observar a partir da fala de Bunker (1985, apud Chaves e Silva, 2016, p.43):

\begin{abstract}
Observa que a Amazônia brasileira foi e continua sendo estruturada pela extração de matéria-prima para exportação e na relação entre sociedade e exploração da natureza, tudo isso subordinado ao sistema político e econômico vigente em cada época, no qual se manifesta uma nova ordem nas formas alternativas de organização do espaço.
\end{abstract}

Dada a desproporcionalidade do capital com as comunidades locais da região do Xingu, a implantação de empreendimentos de grande porte leva à precarização do território devido à divergência de interesses e a utilização dos recursos naturais. Como exposto, justifica-se a execução do projeto na medida em que se analisam e se compreendem os desdobramentos das questões levantadas, das consequências socioespaciais ocasionadas às populações locais em função dos grandes projetos, no caso o papel desempenhado pelo poder público e privado determinados no controle das atividades socioeconômicas no território do Xingu.

Deste modo que a Região do Xingu ganhou visibilidade ao ser construída em 2011 a UHE Belo Monte, sendo esta a terceira maior usina elétrica do Brasil. Portanto, sua construção modificou de forma intensa as relações socioespaciais, que interferiu significativamente no modo de vida da população local.

Dada a dimensão da construção do empreendimento na região, os conflitos sociais foram e são influenciados pelo planejamento do desenvolvimento nacional, tornando-se contraditórios em relação às visões de mundo presentes no espaço amazônico, pois há uma dinâmica do uso e da apropriação dos recursos naturais.

Contudo, como apresenta Hébette (1989) "Isto vai representar a produção de um conjunto de transformações de grande proporção no espaço amazônico, sobretudo com o desenvolvimento da fronteira urbano-industrial na região", visto que Machado (1999), identifica que, “os dados, sobretudo, pelos "Grandes Projetos” marcam, assim, as palavras 
ditas por Martins (2004), a "chegada do estranho" é para as populações das regiões locais da Amazônia, sejam elas indígenas urbanas ou camponesas (HÉBETTE, 1989; 2004).

\section{A EXPERIÊNCIA RECENTE DE GESTÃO E ORDENAMENTO TERRITORIAL EM VITÓRIA DO XINGU}

O município de Vitória do Xingu está localizado no sudoeste Paraense, que faz parte da mesorregião de Altamira. A constituição da cidade está intimamente ligada às missões religiosas. Nos registros históricos datam que as missões ocorreram em meados do século XVIII, onde o Padre Hunderfund adentrou às margens do Rio Xingu com ajuda dos Índios membros da aldeia Xipaia e Curuaia, que em sua missão chegou à Volta Grande do Xingu onde havia um pequeno povoado um pouco acima de onde foi constituída a cidade onde se situa atualmente (IDESP, 2013).

A Missão religiosa foi denominada de Tavaquara, que posteriormente foi completamente abandona devido à expulsão dos Jesuítas do Brasil no período pombalino (1760-1808). Posteriormente, a localidade foi denominada Vitória do Xingu, onde o município foi “criado através da Lei 5.701 de 13 de dezembro de 1991, sancionada pelo então governador Jáder Fontenelle Barbalho, sendo desmembrado de outros dois municípios da RI Xingu, Senador José Porfírio e Porto de Moz” (IDESP, 2013).

O território de Vitória do Xingu possui uma área de 3.135,2 km², cuja a população estimada pelo IBGE em 2019 é de 15.134 pessoas, os dados do último censo de 2010 apontou cerca de 13.431 pessoas, haja vista que a grande maioria da população se localiza na zona rural do município, a densidade demográfica (2010) chega a 4,35 hab $/ \mathrm{km}^{2}$.

Em relação aos serviços básicos em Vitória do Xingu, apontam os dados do IBGE (2019) que:

\footnotetext{
Apresenta $28.9 \%$ de domicílios com esgotamento sanitário adequado, $73.4 \%$ de domicílios urbanos em vias públicas com arborização e $2.4 \%$ de domicílios urbanos em vias públicas com urbanização adequada (presença de bueiro, calçada, pavimentação e meio-fio). Quando comparado com os outros municípios do estado, fica na posição 25 de 144, 11 de 144 e 62 de 144, respectivamente. Já quando comparado a outras cidades do Brasil, sua posição é 3169 de 5570, 2885 de 5570 e 3993 de 5570, respectivamente.
}

As atividades econômicas do município são envoltas da produção e comercialização de produtos agrícolas. Além disso, há extração e comercialização de madeira em tora no município. Os setores econômicos vitoriense que merecem ser relatados também são os 
seguintes: o comércio, o serviço público e a produção agropecuária, como apontam os dados do IDESP (2013), sendo estes inseridos nos setores mencionados:

O extrativismo mineral, indústria de transformação, serviços industriais de utilidade
pública, construção civil, comércio, serviços (de informação; financeiro; atividades
imobiliárias e aluguéis; prestados à empresa, entre outros), administração pública e
atividades de agropecuária (agricultura, pecuária, pesca e extração vegetal) (IDESP,
2013).

No trabalho de campo, o que se verificou foi que embora os recursos públicos estejam sendo utilizados no processo de modernização da cidade, nem sempre há sinergia com a história e as experiências locais principalmente na área urbana. Construção de estádio de futebol, de grandes mercados públicos subutilizados, o asfaltamento das ruas, a sinalização de trânsito em toda parte central da cidade, o que de fato salta aos olhos do observador na cidade é a expansão territorial da cidade por meio de "assentamentos urbanos espontâneos".

$\mathrm{Na}$ análise preliminar de campo observou-se a instalação do Departamento Municipal de Trânsito, o qual trouxe mudanças significativas na mobilidade urbana da cidade, porém a educação e utilização correta da sinalização de trânsito é processual e, por vezes, não é bem receptiva aos moradores, pois causa um estranhamento na forma de utilização das vias públicas.

Em relação à educação, os documentos do EIA/RIMA, previam a construção de 20 escolas no meio urbano e rural. De acordo com os dados expostos pelo empreendedor da UHE Belo Monte, o município teria no total cerca de 32 salas de aula, com capacidade média de 1.648 alunos (EIA RIMA, 2011). No perímetro urbano ainda não foram construídas muitas escolas, mas tem se promovido a revitalização das escolas existentes com boa infraestrutura e condições necessárias para ter um bom aproveitamento escolar e uma creche, investimento empregado a partir dos royalties arrecadados pelo município.

Houve o incentivo à construção de novos espaços de lazer para a população local como praças, quadras poliesportivas, academias ao ar livre, fato este observado em campo que teve uma melhoria na infraestrutura geral da cidade com a instalação da UHE Belo Monte. O setor da cultura e do lazer na cidade de Vitória do Xingu teve investimentos substanciais, o que proporciona, de um olhar geral, a melhoria na qualidade de vida da população vitoriense.

O estádio da cidade foi remodelado e revitalizado com tecnologia de padrão atual e, em observação em campo, o estádio é pouco aproveitado, considerando o seu caráter espetacularizado que acompanha o padrão das grandes arenas futebolísticas do contexto global, sendo utilizado, na maioria das vezes, apenas em eventos oficiais da cidade. As figuras 
2 e 3 exemplificam esse caráter moderno e espetacular do Estádio Municipal de Futebol Padre João - Arena Xingu.

Figura 02: Estádio Municipal de Futebol Padre João - Arena Xingu

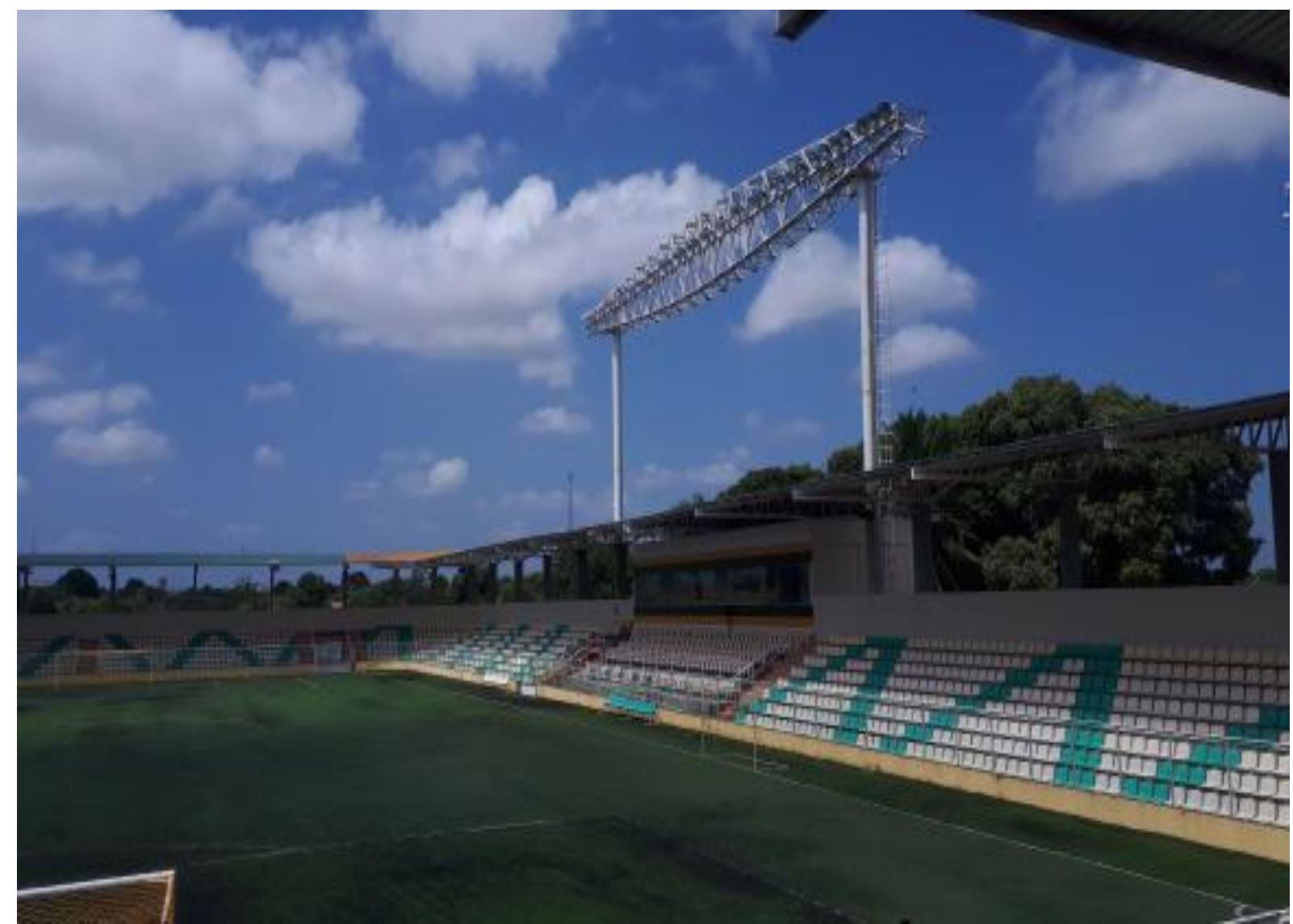

Figura 02: Visão parcial da Arena Xingu

Fonte: Trabalho de Campo, Set. 2019. 
Figura 03: Estádio Municipal de Futebol padre João-Arena Xingu

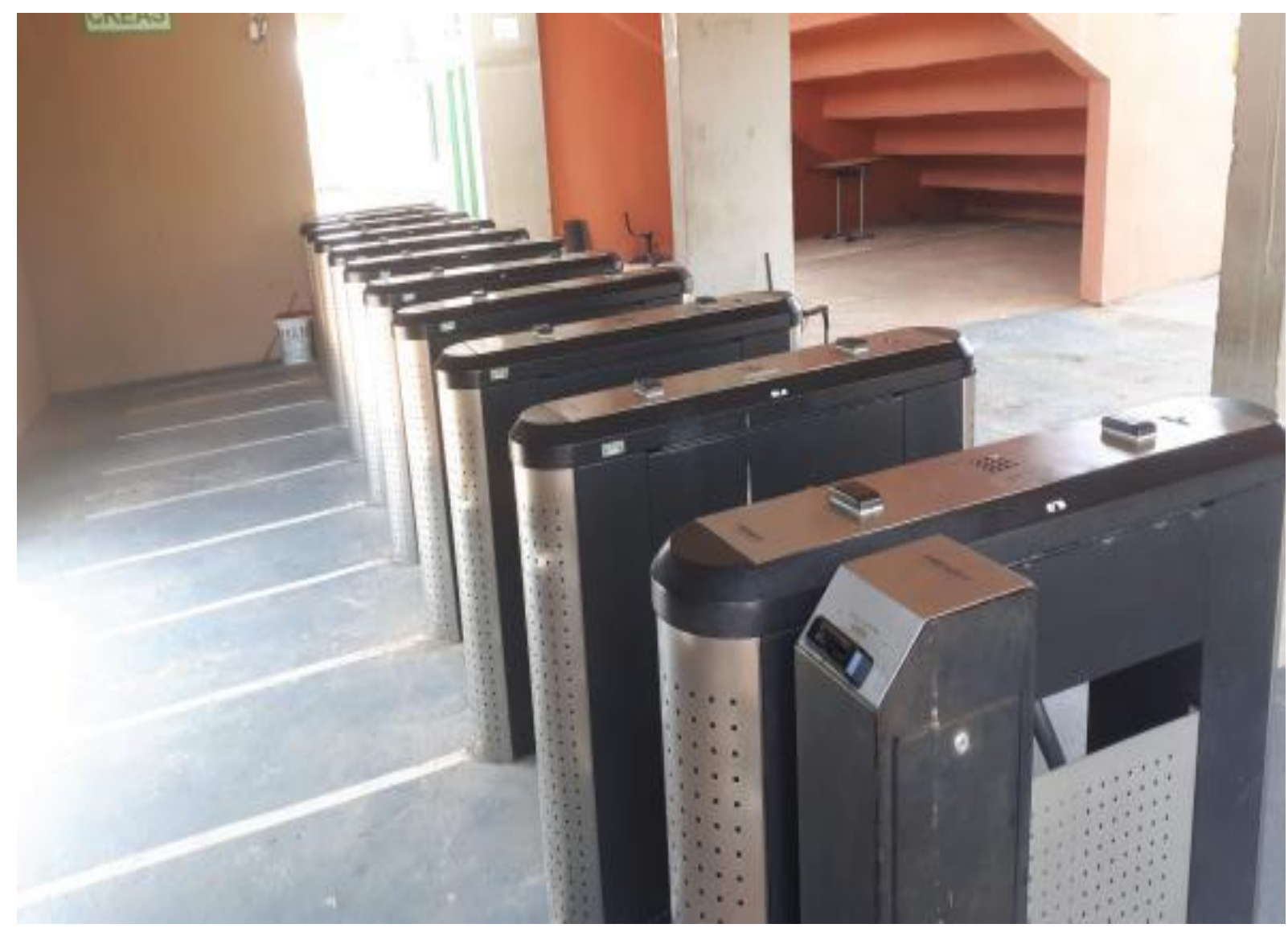

Figura 03: Visão das Catracas Arena Xingu

Fonte: Trabalho de Campo, Set. 2019.

Observa-se nas figuras 02 e 03 que a "Arena Xingu" destoa de todos os estádios que temos na Amazônia, mais ainda quando se considera o fato de se tratar de uma pequena cidade com pouca tradição no futebol profissional do Estado do Pará. Mesmo quando comparado aos estádios de equipes profissionais e tradicionais da região, como Remo e Paissandu, a referida arena municipal se destaca em termos de modernidade, tendo custado 6,5 milhões de reais e inaugurada com presenças ilustres do futebol como, por exemplo, Zico (Arthur Antunes Coimbra).

Pode-se dizer ainda que, numa análise preliminar, tem ocorrido mudanças significativas no município, pois com a instalação do empreendimento de Belo Monte, a empresa foi instruída a cumprir cerca de 40 condicionantes para que houvesse investimentos nos municípios diretamente afetados. Com isso houve um crescimento em todos os setores, pois com os investimentos e a inserção dos royalties que a cidade recebeu, proporcionou a melhoria na infraestrutura resultando em melhorias no padrão de vida da população local.

Com o cumprimento das condicionantes houve a ampliação do setor da saúde, com a construção e revitalização de postos de saúde e hospital municipal, implantação de serviço de 
saneamento básico em toda extensão da cidade como rede de esgoto, construção da estação de tratamento de água e esgoto, além da pavimentação das vias públicas, dos mercados públicos e o aumento na geração de empregos em distintos setores, desde a geração de trabalho formal e informal (EIA-RIMA, 2009). Nas figuras 04 e 05 podem-se exemplificar essas mudanças que vêm ocorrendo na cidade.

Figura 04: Hospital Municipal de Vitória do Xingu

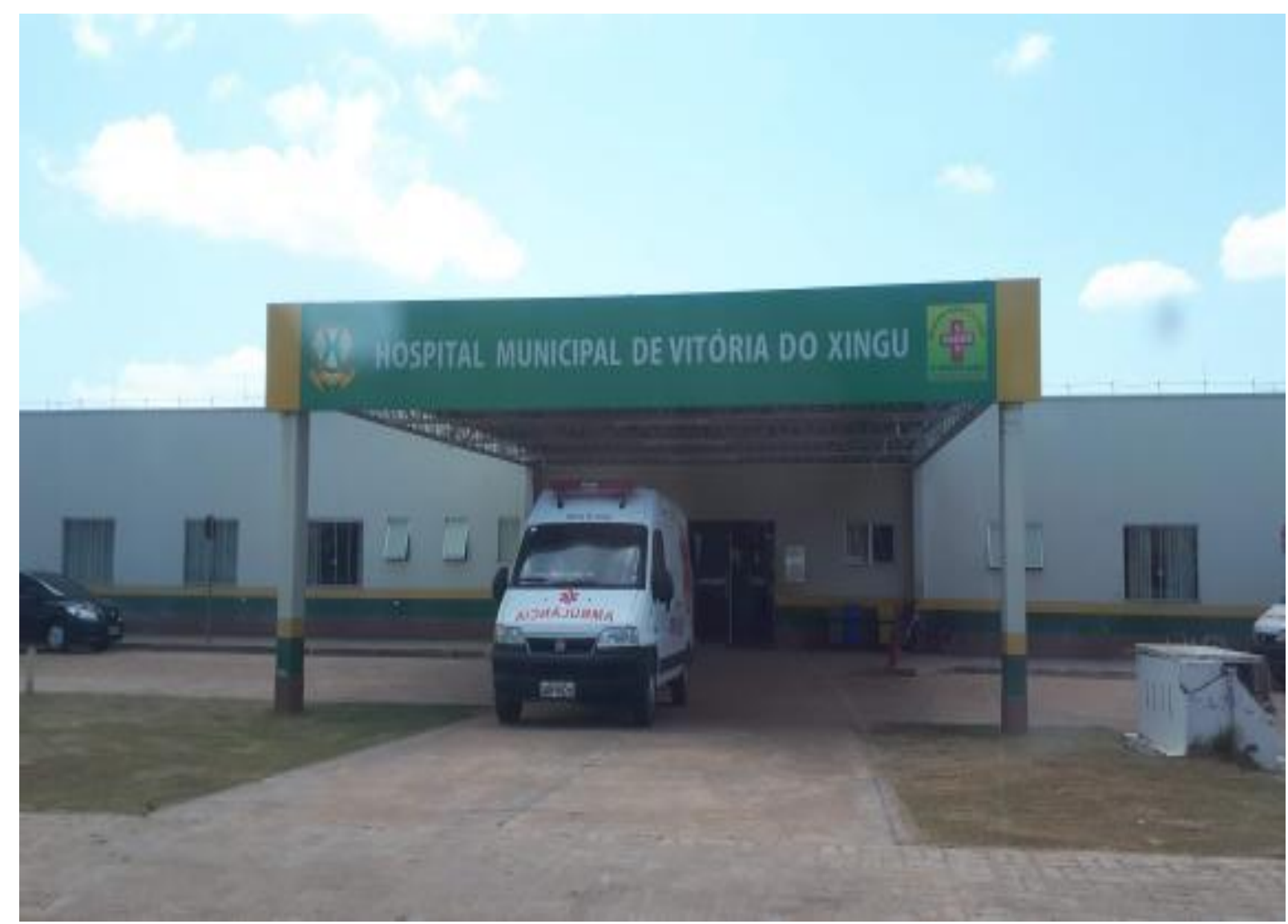

Figura 04: Visão frontal do Hospital Municipal de Vitória do Xingu

Fonte: Trabalho de Campo, Set. 2019. 
Figura 05 Mercado Municipal de Vitória do Xingu

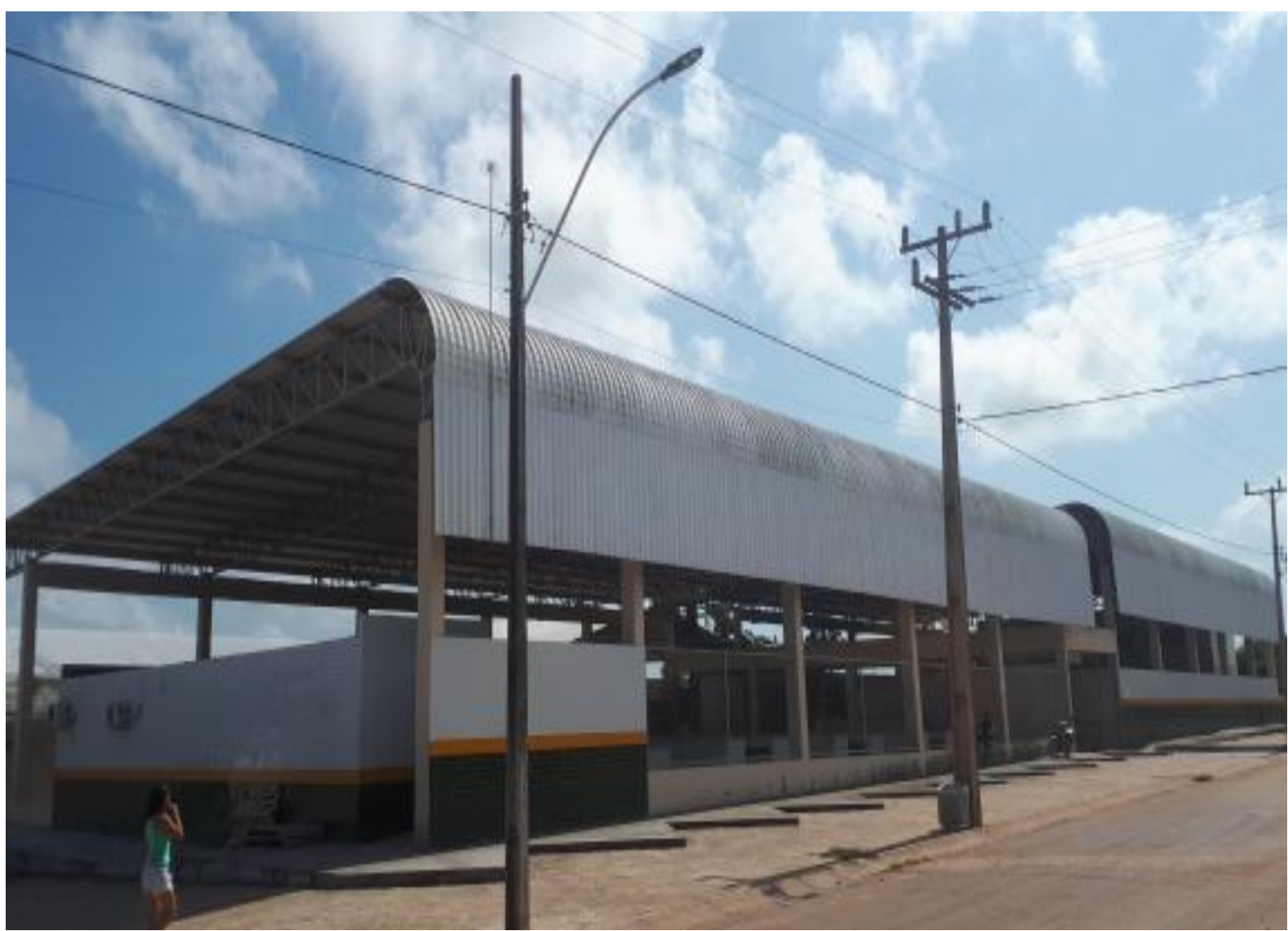

Fonte: Trabalho de Campo, Set. 2019.

Vale ressaltar que as ações de assistência social no município dependem inteiramente do convênio do município com a empresa Norte Energia para que haja o desenvolvimento das atividades previstas nas condicionantes face à instalação do empreendimento hidrelétrico. Não havendo uma boa relação entre estes órgãos, tem-se uma disparidade e atraso na construção ou execução das melhorias materiais e imateriais da população diretamente afetada pelo empreendimento.

O aumento considerável no fluxo migratório para a região de construção do empreendimento da UHE Belo Monte, em específico para a cidade de Vitória do Xingu, agravou consideravelmente, isso se justifica pela necessidade de reforço da hierarquia funcional da cidade, visto que esta era de pequeno porte e os serviços básicos eram limitados às necessidades das populações locais.

No ano de 2012, o perímetro urbano teve a ocorrência de muitas apropriações "ilegais" em torno da cidade, áreas estas não habitadas anteriormente à construção do empreendimento, que promoveu a atração de migrantes do campo e de outras regiões do país em busca de 
trabalho na obra de Belo Monte e que viam em Vitória do Xingu uma possibilidade de se reproduzir, dado o nível de especulação imobiliária que impossibilitava o acesso à terra em Altamira.

Essas áreas passaram a ser povoadas com habitações voltadas para atender ao interesse desses grupos sociais excluídos, que de alguma maneira chegaram à cidade e que demandam espaços para se reproduzir socialmente. Ressalta-se ainda que a necessidade de entrar numa discussão acerca da diversidade em termos de diferenças étnicas, uma vez que se trata de um território municipal com forte presença indígena, exigiria uma reflexão centrada nesse aspecto, o que de imediato reconhecemos não ser possível nos limites desse primeiro artigo preliminar.

O resultado imediato desse processo é o aparecimento de espaços segregados no interior da cidade e que tem contribuído significativamente para sua expansão físicoterritorial. Uma explicação provisória para essa expansão, via assentamentos precários no interior da cidade, se deu pelo fato da população sofrer com o aumento do preço dos aluguéis, devido à especulação gerada pelo grande empreendimento, o que produziu como efeito a "ocupação desordenada" do solo, ou seja, houve a necessidade de ocupar novas áreas no perímetro urbano para que se pudesse usufruir do direito à moradia.

Se em outras cidades de maior porte este processo se dá pelo envolvimento dos agentes como o Estado, incorporadoras imobiliárias, dentre outros, em Vitória do Xingu este processo se deu por agentes sociais excluídos, que foram espoliados de determinadas áreas da cidade ou até pelos fatores econômicos oriundos dos altos preços da terra urbana, levando-os à ocupação e novas demandas por infraestrutura nessas novas localidades, ocasionando a criação dos bairros periféricos.

\section{CONSIDERAÇÕES FINAIS}

O objetivo proposto neste artigo foi de analisar as mudanças nas práticas de gestão e ordenamento territorial em Vitória do Xingu a partir da implantação da Usina Hidrelétrica de Belo Monte (UHBM), após as análises dos dados preliminares coletados e do trabalho de campo buscou-se atentar às transformações ocorridas no território de Vitória do Xingu com o propósito de averiguar a gestão e o ordenamento territorial, pois este é entendido como sendo, um instrumento de articulação interinstitucional e de articulação transetorial, que tem como objetivo um planejamento integrado e articulado junto à ação pública, consequentemente, dada a compatibilidade de políticas públicas, no rebatimento do espaço, integrado à ação do poder público. 
Foi notório que a construção do empreendimento hidrelétrico de Belo Monte, alterou consideravelmente não apenas o espaço físico (meio ambiente construído), mas também as relações socioespaciais do município, pois o movimento do território incorpora novas estruturas e formas para o desenvolvimento local, cujo propósito é a melhoria na qualidade de vida da população local. É inevitável afirmar que este "território em movimento" está apena no início, dado o tempo de inserção do empreendimento hidrelétrico no município.

Portanto, os questionamentos quanto à gestão e ao ordenamento territorial no município estão apenas começando, pois a nova dinâmica estabelecida no território e o dado momento histórico estão em transformação. Mediante a este fato, cabe a relevância de acompanhamento e pesquisa, pois a perspectiva é inovadora ao revelar os aspectos de transformação ocorridos no território vitoriense, mostrando as dimensões "contra" e a "favor" do empreendimento e quanto ao rebatimento da gestão e do ordenamento do território face à instalação do empreendimento hidrelétrico de Belo Monte.

Além disso, deve-se ressaltar que os dados muito preliminares que temos, apontam na direção de que a gestão e o ordenamento territorial estão voltados para a modernização do território e o desenvolvimento econômico, havendo ainda muitos limites no que se refere ao processo de autonomização individual e coletiva da população, bem como em termos de melhoria da qualidade de vida e da justiça social e ambiental.

A forma como se tem pensado o desenvolvimento indica na direção da lógica exógena do desenvolvimento, na cresça ainda viva dos polos de desenvolvimento, que postula que o crescimento não aparece em todo lugar, mas em polos específicos de intensidades variadas que vão se espalhando pelo conjunto do sistema econômico. Desse modo, caberia aos lugares tornarem-se atrativos a essa "economia global" - a expansão geográfica do capital - e não protagonistas autônomas do desenvolvimento, inclusive com capacidade de superar essa visão economicista, eurocêntrica e teleológica.

\section{REFERÊNCIAS}

\section{Fontes eletrônicas}

APROVEITAMENTO Hidrelétrico Belo Monte: relatório de impacto ambiental - RIMA. Brasília: Eletrobrás, 2009.

ATHAS DE DESENVOLVIMENTO HUMANO. VITÓRIA DO XINGU/ PA. Acesso em: 18/10/2019. Disponível em: http://www.atlasbrasil.org.br/2013/pt/perfil_m/vitoria-doxingu_pa . 
BNDES. Panorama Mundial: O desempenho da economia mundial e perspectivas para os próximos anos. In: Sinopse Internacional. Autores: Alem, A.C., et alii. BNDES: Rio de Janeiro, n. 12, set. 2009.

HIDRELÉTRICA BELO MONTE. Acesso em: 05/09/2019. Disponível em: http://www.blogbelomonte.com.br.

Acesso em: 12/08/2019. Disponível em: http: //www.ibama.gov.br.

IBGE. Vitória do Xingu Pará. Acesso em: 18/10/2019. Disponível em: https://cidades.ibge.gov.br/brasil/pa/vitoria-do-xingu/panorama.

IDESP. Instituto de Desenvolvimento Econômico,Social e Ambiental do Pará Estatística Mun icipal de Vitória do Xingu. Disponível em http:// www.idesp.pa.gov.br/paginas/produos/Estati stica Municipal /pdf/Vitoria do Xingu.pdf. Acesso em 19 de outubro de 2019.

INSTITUTO HUMANISTAS UNISINOS. Acesso em: 04/10/ 2018. http://www.ihu.unisinos.br/78-noticias/521600-grandes-projetos-e-desenvolvimento-regionalna-amazonia-artigo-de-edilberto-sena.

IPEA. A função socioambiental do patrimônio da União na Amazônia / organizador: Fábio Alves. Brasília: IPEA, 2016. 359 p. Acesso em: 18/10/2019. http://www.ipea.gov.br/portal/images/stories/PDFs/livros/livros/160623_livro_funcao_socioa mbiental_cap06.pdf.

INSTITUTO DE PESQUISA ECONÔMICA APLICADA. Observatório da Função Socioambiental do Patrimônio da União na Amazônia. Relatório de Pesquisa. Relatório Territorial da Região do Médio Xingu. Rio de Janeiro: IPEA, 2015.

MINISTÉRIO DA INTEGRAÇÃO NACIONAL. Plano de Desenvolvimento Regional Sustentável do Xingu, Relatório Técnico. Disponível em:http://www.mi.gov.br/c/document_li brary/get_file?uuid=9cd2d8c-9e8c-4db0-a362 f7f4af1e9b96\&groupId=24915. Acesso em: 10 de Outubro de 2018.

MINISTÉRIO DA INTEGRAÇÃO NACIONAL (MI). “Para pensar uma Política Nacional de Ordenamento Territorial". Anais da Oficina sobre a Política Nacional de Ordenamento Teritor ial, Brasília, Ministério da Integração Nacional, Secretaria de Políticas de Desenvolvimento Regional (SDR). Brasília: MI, 2005. 78 p.

RIMA - Relatório de Impacto Ambiental. 2009.

SEPOF, Secretaria de Planejamento, Orçamento e Finanças do Estado do Pará. (2011). Estatísticas municipais: Vitória do Xingu: SEPOF. Vitória do Xingu comunidades. Acesso: 18/10/2019. Disponível em: http://vitoriadoxingu_pa.no.comunidades.net/.

\section{Revistas científicas}

ANDRADE, Manuel Correia de. O Meio-Norte. edição rev. e atual. São Paulo: Brasiliense, p. 81-117, 1977. 
Aproximación al problema. In: CELADE - Centro Latinoamericano y Caribeño de Demografía. Efectos demograficos de grandes proyectos de desarrollo. San José, Imprenta Nacional, 1990. 350p. (p. 3-13).

BOISIER, Sérgio. Desarrollo regional endógeno en Chile. Utopía o necesidade Ambiente y Desarrollo. Santiago de Chile, v. 9, 1993.

BOISIER, Sergio. El vuelo de una cometa. Una metáfora para una teoría del desarrollo territorial. Revista EURE. Revista de Estudios Urbano Regionales, 1993, 23.69. BUENO SÁNCHEZ, Eramis. Efectos demograficos de proyectos de desarrollo.

BUNKER, S. G. Underdeveloping the Amazon: Extraction, Unequal Exchange, and the Failure of the Modern State. Chicago: The Universityof Chicago Press, 1985.

CHAVES, D. A; SILVA, J. M. P. da. O Plano Nacional da Mineração (2010-2030) e seu Rebatimento no Território Amazônico. Revista Política e Planejamento Regional, Rio de Janeiro, v. 3, n. 1, janeiro/ junho 2016, p. 39 a 52. ISSN 2358-4556.

DALLABRIDA, Valdir Roque. A gestão territorial através do diálogo e da participação. Scripta Nova. Revista Electrónica de Geografía y Ciencias Sociales, 2007, 11.245: 20.

DALLABRIDA, Valdir Roque. Sustentabilidade e endogenização: novos paradigmas para o desenvolvimento regional. In: BECKER, Dinizar F.; BANDEIRA, Pedro $S$. Desenvolvimento Local-Regional: determinantes e desafios contemporâneos. Santa Catarina: EDUNISC, 2000.

DE CASTRO, Raifran Abidimar.Os grandes projetos econômicos, a ação estratégica de do minação empresarial e as comunidades rurais. Revista Espaço Acadêmico, v. 17, n. 193, p. 113-124, 2017.

DUNCAN, M. Gestão Territorial, 2009.

FERREIRA, Antônia MM; SALATI, Enéas. Forças de transformação do ecossistema amazônico. Estudos avançados, v. 19, n. 54, p. 25-44, 2005.

GOMEZ-OREA, Domingo. Ordenación del território. Madrid: ITGE, 1993.

HÉBETTE, Jean. A ocupação humana recente da microrregião de Marabá. In: Hébette, J. (Org.). Cruzando a fronteira: 30 anos de estudo sobre o campesinato na Amazônia. v. IV. Belém, PA: EDUFPA, 2004. p. 63-71.

O cerco está se fechando. Rio de Janeiro: FASE,1991.

. A ocupação humana recente da microrregião de Marabá. Cruzando a fronteira, 2004, 30: 63-71.

KAYSER, Bernard. Tipologia dos espaços geográficos no mundo subdesenvolvido. Orientação, São Paulo, n. 4, p. 25-30, 1969. 
Impactos Regionais de "Grandes Projetos" e as Possibilidades de reorganização do Espaço na Periferia Amazônica em Aragon, L.E. (ed.) A desordem ecológica na Amazônia. Série Cooperação Amazônica 7 (Belém: UNAMAZ, UFPAM, 1991a), pp. 253-269.

MOREIRA, R. P.; HERRERA, J. A. A expansão do capital por grandes projetos: desafios ao ordenamento do território no município de Altamira-Pará. Revista GeoNorte, v. 7, p. 13151330, 2013.

MOREIRA, R.P.; HERRERA, J.A. Ordenamento do Território e a Materialização do Desenvolvimento Geográfico Desigual: A Construção da Usina Hidroelétrica Belo Monte entre (1975-2011) no Estado do Pará. Boletim Amazônico de Geografia, v. 3, p. 71-93, 2015.

MOREIRA, Rodolfo Pragana; HERRERA, José Antônio. Ordenamento Territorial e Criaç ão dos RUC: Uma leitura geográfica a partir dos impactos no Baixão do Tufi em Altamira Pa rá. Inter Espaço: Revista de Geografia e Interdisciplinaridade, v. 4, n. 12, p. 32-44, 2018.

NEVES, I. C; CARVALHO, B. G; CORNÉLIO, G. S. Expansão urbana e segregação sócio-espacial: uma análise da cidade de Altamira Pará face ao empreendimento Hidrelétrico de Belo Monte. Revista do Instituto Histórico e Geográfico do Pará (IHGP). ISSN 2359-0831, Belém-PA, p. 99 - 116, 01 jul. 2016.

\section{Livros}

ACSELRAD, Henri; MELLO, Cecília Campello Amaral; BEZERRA, Gustavo das Neves. O que é justiça ambiental. Rio de Janeiro: Editora Garamond, 160 p. ISBN: 9788576171591 , 2009.

ANDRADE, Manuel Correia de. Espaço, polarização e desenvolvimento. São Paulo: Ed. Grijalbo, 1977.

HAESBAERT, Rogério. Ordenamento territorial. Boletim goiano de Geografia, v. 26, n. 1, p. 117-124, 2006.

LEFEBVRE, Henri; NICHOLSON-SMITH, Donald. The production of space. Blackwell: Oxford, 1991.

MARX, K. ; Engels, F. A ideologia alemã. São Paulo: Ed. Grijalbo, 1977.

MARX, K. O capital: crítica da economia política. Vol. 01. (Capítulos I - XII). (Tradução Regis Barbosa; Flávio R. Kothe). São Paulo: Ed. Nova Cultural, 1996a.

O capital: crítica da economia política. Vol. 02. (Capítulos XIII - XXV).

(Tradução Regis Barbosa; Flávio R. Kothe). São Paulo: Ed. Nova Cultural, 1996b.

Para a crítica da economia política. São Paulo: Ed: Abril Cultural, 1982.

SANTOS, M. A Natureza do Espaço: Técnica e Tempo. Razão e Emoção. $4^{\circ}$ Edição. São Paulo. Edusp. 2013. 
São Paulo, 2006.

A natureza do espaço. 4. ed. 2. reimpr. São Paulo: Editora da Universidade de

SANTOS, Milton; SILVEIRA, Maria Laura. O Brasil: território e sociedade no início do século XXI. 5a . Edição. Rio de Janeiro: Record, 2003.

SOUZA, Marcelo Lopes de. Os conceitos fundamentais da pesquisa sócio-espacial. Rio de Janeiro: Bertrand Brasil, 2013.

Recebido em: 28/10/2019

Aprovado em: 23/11/2019 